\title{
GRID-CHARACTERISTIC METHOD FOR NUMERICAL MODELING OF WAVE PROCESSES IN THREE-DIMENSIONAL PROBLEMS OF DYNAMIC LOADING OF COMPLEX STRUCTURES
}

\author{
Igor B. Petrov, Alena V. Favorskaya, Nikolay I. Khokhlov, Vladislav A. Miryakha,
} Alexander V. Sannikov, Katerina A. Beklemysheva, Vasiliy I. Golubev

Moscow Institute of Physics and Technology, Department of Computer Science, http:/ /www.mipt.ru 141701 Dolgoprudny, Moscow region, Russian Federation

petrov@mipt.ru, aleanera@yandex.ru,k_h@inbox.ru,vlad.miryaha@gmail.com, donxenapo@gmail.com, amisto@yandex.ru,w.golubev@mail.ru

Abstract. This paper is to inform about the numerical method of computer modeling of wave propagation in three-dimensional problems of dynamic loading of complex structures. As a method of modeling uses grid-characteristic method. This method uses unstructured tetrahedral hierarchical meshes, a multiple time step and the high-order interpolation, it has the precise formulation of contact conditions. The use of this grid-characteristic method makes it possible to use the multiple time step and thereby increase productivity and significantly reduce the computation time. This method is used here for modeling the railway defectoscopy for security and timely detection of defects. The comparison of wave patterns that occur during the transmission of elastic waves in the rail obtained by grid-characteristic method on curvilinear structured grids and discontinuous Galerkin method on unstructured tetrahedral grids was done.

Keywords: grid-characteristic method, computer simulation, discontinuous Galerkin method, defectoscopy of railway.

PACS: 02.60.Cb, 02.70.-c, 02.70.Dh, 89.20.Ff

Bibliography -37 references

Received 06.11.2014

RENSIT, 2015, 7(1):34-47

DOI: $10.17725 /$ rensit.2015.07.034

\section{CONTENTS}

1. INTRODUCTION (34)

2. Features of Numerical Modeling (35)

3. GRID-Characteristic METHod (36)

4. Discontinuous Galerkin method on UNSTRUCTURED TRIANGULAR MESHES (37)

5. Non-Destructive testing of railiway (38) 5.1. Wave propagation in the rail (39)

5.2. The propagation of elastic waves in the moving system "wheel-rail" (40)

5.3. Diagnosis of defects of rail in an early stage of formation (41)

5.4. Numerical simulation of wave pattern in the damaged rail (41)

5.5. Propagation of ultrasonic waves in the profile of the rail top with a horizontal bundle (43)

5.6. FINDING THE INCLUSION OF KARST IN THE GROUND UNDER THE EMBANKMENT (45)

6. Conclusions (45)

REFERENCES (46)

\section{INTRODUCTION}

Solving up-to-date problems of computer modeling spatial dynamic processes in complex heterogeneous media including problems about wave propagation in anisotropic media of composed materials under dynamic loading requires to using more complicated mechanical mathematical models. Since the system of equations describing wave propagation in anisotropic elastic media [1,2] is hyperbolic and high accurate calculations of wave processes are needed, the use of grid-characteristic method is optimal $[3,4,5]$. As against method of finite elements and discontinuous Galerkin method which are used in most applied software for modeling of deformable solid bodies, the grid-characteristic method takes into account characteristic properties of the given system of 
equations. This feature allows to model wave propagation in the volume, wave scattering on every interfaces and to obtain full solution of dynamic interface problems. This allows to take into account the influence of all interface and boundary conditions in the given media. Grid-characteristic method allows to obtain high time and spatial resolution and to calculate all components of stress tension and velocity in every point of the given media. Also this method allows to investigate the influence of damage zones on the wave pattern. One can use different kinds of damage criteria and damage models. Also this method allows to use different material models (linear-elastic media, viscoelastic media, viscoelastic plastic media) including anisotropic case. Also one can use the algorithm of friction calculation using grid-characteristic method.

Grid-characteristic method allows to use monotonous finite-difference schemes of high order accuracy, use correct numerical algorithms on the interfaces and boundaries. Using hierarchical grids allows to obtain last amount of non-homogeneous inclusions in modeled media. Also one can use high order interpolation on triangular and tetrahedral grids $[6,7]$, including piecewise parabolic, hybrid and interpolation with limiters. The use of grid-characteristic method [8-10], and also the use of discontinuous Galerkin method [11] for elastic media allows to realize accurate definition of boundary conditions with given velocity at the boundary, given traction and interface conditions of continuous traction and velocity and free sliding. Some examples of using grid-characteristic method with parabolic interpolation with limiters on unstructured triangular grids for solving problems of wave propagation in heterogeneous spatial constructions are discussed at [12], and using high order interpolation on unstructured tetrahedral grids is discussed at [13].
$3 D$ problems needs to use larger amount of data then $2 D$ problems. So it is needed to use high performance computer systems. The developed algorithm was paralleled with optimal using of system recourses.

In order to obtain thorough and detailed descriptions for all wave processes in the vicinity of all non-homogeneities present in the problem, a rather detailed mesh has to be used. The smaller the heterogeneous inclusions to be studied, the more time steps and operations at each time layer have to be performed. However, in most cases, nonhomogeneities are localized within a small volume inside the integration domain.

The use of hierarchical meshes with condensations at the locations of the nonhomogeneities is optimal for the given statement of the problem.

In grid-characteristic methods, time integration steps depend directly on the size of the minimum space steps. Thus, the use of standard hierarchical meshes does not reduce the number of time steps but only reduces the number of operations at each time layer.

The performed theoretical and numerical investigations showed that the use of gridcharacteristic methods makes it possible to use dedicated hierarchical meshes with a multiple step. In addition to a multiple space step, a multiple time step may be introduced, which will reduce not only the number of operations required for integrating problems at each time layer but also the number of time steps carried out in the segment of the integration domain with no heterogeneities and with a coarser mesh.

\section{FEATURES OF NUMERICAL MODELING}

The system of equation describing elastic waves in anisotropic linear-elastic media in the $3 D$-case with coordinates $\left(x_{1}, x_{2}, x_{3}\right)$ could be written as follows 
36 IGOR B. PETROV, ALENA V. FAVORSKAYA, NIKOLAY I. KHOKHLOV, VLADISLAV A. MIRYAKHA, ALEXANDER V. SANNIKOV, KATERINA A. BEKLEMYSHEVA, VASILY I. GOLUBEV

$$
\begin{aligned}
& \rho \dot{v}_{i}=\nabla_{i} \sigma_{i j}, \\
& \dot{\sigma}_{i j}=q_{i j k l} \dot{\varepsilon}_{k l}+F_{i j} .
\end{aligned}
$$

In this formula $\varrho$ is density, $\nu_{i}$ are components of velocity in this medium, $\sigma_{\mathrm{ij}}$ и $\varepsilon_{\mathrm{ij}}$ are components of stress tension and deformation tension, $\nabla_{i}-$ ковариантная derivative with respect to $x_{\rho} F_{i j}$ - additional right side. The view of tensor $q_{i j k l}$ of rank 4 is formed by rheology of given anisotropic elastic medium. In the case of linear elastic media they could be written as follows

$$
q_{\mathrm{ijkl}}=\lambda \delta_{\mathrm{ij}} \delta_{\mathrm{kl}}+\mu\left(\delta_{\mathrm{ik}} \delta_{\mathrm{jl}}+\delta_{\mathrm{il}} \delta_{\mathrm{jk}}\right) \text {. }
$$

In this equation, $\lambda$ and $\mu$ are Lame's parameters, and $\delta_{\mathrm{ij}}$ is Chronicler's symbol.

The equation (1) represents the equation of motion, and the equation (2) represents 6 relationships of given rheology. Vector of unknown fields is composed from 9 components and takes the following form

$\mathrm{u}=\left\{\nu_{1}, \nu_{2}, \nu_{3}, \sigma_{11}, \sigma_{12}, \sigma_{13}, \sigma_{22}, \sigma_{23}, \sigma_{33}\right\}^{\mathrm{T}}$.

Then, mentioned models of solid bodies provides the expression for this system of equations (1) to be represented in the following matrix form [14]:

$$
\frac{\partial \boldsymbol{u}}{\partial t}=\sum_{i=1}^{3} \boldsymbol{A}_{j} \frac{\partial \boldsymbol{u}}{\partial x},
$$

In last equation $A_{j}$ is the $9 \mathrm{x} 9$ matrix:

$$
A_{1}=\left|\begin{array}{ccccccccc}
0 & 0 & 0 & -\frac{1}{\rho} & 0 & 0 & 0 & 0 & 0 \\
0 & 0 & 0 & 0 & -\frac{1}{\rho} & 0 & 0 & 0 & 0 \\
0 & 0 & 0 & 0 & 0 & -\frac{1}{\rho} & 0 & 0 & 0 \\
-(\lambda+2 \mu & 0 & 0 & 0 & 0 & 0 & 0 & 0 & 0 \\
0 & -\mu & 0 & 0 & 0 & 0 & 0 & 0 & 0 \\
0 & 0 & -\mu & 0 & 0 & 0 & 0 & 0 & 0 \\
-\lambda & 0 & 0 & 0 & 0 & 0 & 0 & 0 & 0 \\
0 & 0 & 0 & 0 & 0 & 0 & 0 & 0 & 0 \\
-\lambda & 0 & 0 & 0 & 0 & 0 & 0 & 0 & 0
\end{array}\right|,
$$

\section{INFORMATION TECHNOLOGIES}

System of equations (2) is hyperbolic, therefore all of matrixes $A_{j}$ obtains 9 real eigenvalues and the basis composed form 9 eigenvectors.

This form is classical form for representing systems of equations in computational mathematics for development of finitedifference and grid-characteristic schemes.

\section{GRID-CHARACTERISTIC METHOD}

In the case of numerical simulation of dynamic processes in deformable solid bodies the use of grid-characteristic method begins from dimensional splitting. So one can consider 3 systems of equations

$$
\frac{\partial \boldsymbol{u}}{\partial t}=\boldsymbol{A}_{j} \frac{\partial \boldsymbol{u}}{\partial x_{j}}, j=1,2,3 .
$$

All of these 3 systems is hyperbolic and obtains of full set of eigenvectors and real 
eigenvalues. So all of these 3 systems could be represented in the following form

$$
\frac{\partial \boldsymbol{u}}{\partial t}=\Omega_{j}^{-1} \Lambda_{j} \Omega_{j} A_{j} \frac{\partial \boldsymbol{u}}{\partial x_{j}},
$$

there matrix $\boldsymbol{\Omega}_{\mathrm{j}}$ is the matrix composed from eigenvectors, $\boldsymbol{\Lambda}_{\mathrm{j}}$ is diagonal matrix composed from eigenvalues. For all directions matrix $\boldsymbol{\Lambda}$ takes the following form

$$
\boldsymbol{\Lambda}=\operatorname{diag}\left\{c_{p},-c_{p}, c_{3}, c_{3}, c_{3},-c_{3}, 0,0,0\right\} \text {. }
$$

In last equation $c_{p}=\sqrt{(\lambda+2 \mu) / \rho}$ is the speed of $P$-waves, $c_{s}=\sqrt{\mu / \rho}$ is the speed of $S$-waves.

After the following exchange of vectors of unknown fields $\nu=\boldsymbol{\Omega u}$ all of system of equations (3) could be represented as 9 independent scalar transport equations (index $j$ is not used in all following equations in which it is possible)

$$
\frac{\partial v}{\partial t}+\Lambda \frac{\partial v}{\partial x}=0
$$

$1 D$ transport equations are solved using grid-characteristic method or some kind of finite-difference schemes.

Then all component of vector $v$ are founded, one can obtain the solution of initial system

$$
\mathbf{u}^{\mathrm{n}+1}=\Omega^{-1} \boldsymbol{\nu}^{\mathrm{n}+1} \text {. }
$$

In this paper we use TVD schemes [15] of second order of accuracy. In software are used 15 limiters [16] to obtain monotonous solutions in the case of high saltuses. In this paper we use superbee limiter [17]:

$$
\phi_{s b}(r)=\max [0, \min (2 r, 1), \min (r, 2)] \text {. }
$$

Also we use monotonous grid-characteristic schemes. The principles of these schemes are discussed in [18]. In our software we use schemes of 2-4 orders of accuracy. Most of numerical calculations was done using the scheme of 4 order of accuracy. In the case of $1 D$ transport equation in takes the following form

$$
u_{t}+\lambda u_{x}=0, \sigma=\lambda \tau / h:
$$

$$
\begin{aligned}
& u_{m}^{n+1}=u_{m}^{n}-\sigma\left(\Delta_{1}-\sigma\left(\Delta_{2}-\sigma\left(\Delta_{3}-\sigma \Delta_{4}\right)\right)\right), \\
& \Delta_{1}=\frac{1}{24}\left(-2 u_{m+2}^{n}+16 u_{m+1}^{n}-16 u_{m-1}^{n}+2 u_{m-2}^{n}\right), \\
& \Delta_{2}=\frac{1}{24}\left(-u_{m+2}^{n}+16 u_{m+1}^{n}-30 u_{m}^{n}+16 u_{m-1}^{n}-u_{m-2}^{n}\right), \\
& \Delta_{3}=\frac{1}{24}\left(2 u_{m+2}^{n}-4 u_{m+1}^{n}+4 u_{m}^{n}-2 u_{m-2}^{n}\right), \\
& \Delta_{4}=\frac{1}{24}\left(u_{m+2}^{n}-4 u_{m+1}^{n}+6 u_{m}^{n}-4 u_{m-1}^{n}+u_{m-2}^{n}\right) .
\end{aligned}
$$

Rather than, we use grid-characteristic criteria for obtaining monotonous schemes [18]. In the case of positive $\lambda$ this criteria takes the following form:

$$
\min \left\{u_{m}^{n}, u_{m-1}^{n}\right\} \leq u_{m}^{n+1} \leq \max \left\{u_{m}^{n}, u_{m-1}^{n}\right\} .
$$

In the case of negative $\lambda$ in takes symmetric form. In the simplest realization one can use limiter in the following form

$$
u_{m}^{n+1}= \begin{cases}\max \left\{u_{m}^{n}, u_{m-1}^{n}\right\}, & u_{m}^{n+1}>\max \left\{u_{m}^{n}, u_{m-1}^{n}\right\}, \\ \min \left\{u_{m}^{n}, u_{m-1}^{n}\right\}, & u_{m}^{n+1}<\min \left\{u_{m}^{n}, u_{m-1}^{n}\right\} .\end{cases}
$$

In [18] are show that this limiter saves 4 order of accuracy in the areas of smooth solution (and grid-characteristic criteria is true). In the case of high gradients of solution the order of scheme becomes equal to 3 .

\section{DISCONTINUOUS GALERKIN METHOD ON UNSTRUCTURED TRIANGULAR MESHES}

In the most cases of rail non-destructive testing, traumatology, seismology and etc. for obtaining numerical solutions of wave processes within elastic and acoustic media and also for development of interface conditions one can use unstructured tetrahedral meshes and discontinues Galerkin method [19] (this method is the evolution of classical method of finite elements for solutions with high gradients). This method is known as method of high order of accuracy for both spatial and time coordinates. Galerkin method was realized in our software and shows good results and high numerical accuracy. Also we made comparison 
between solutions obtained by Galerkin method and grid-characteristic method.

We use the approach [20], the core of this approach is using analytical solution of Ryman problem [21] at the interface between acoustic and elastic media. Discontinuous Galerkin method allows to use high order polynomials and so provides obtaining of high accuracy for all spatial coordinates. This is critical for numerical simulation of wave processes in heterogeneous media. We use Lagrange polynomials as basic polynomials [22]. Time integration was done using 7-stage Dormand-Prince integrator [23, 24] of 5 order of accuracy (It is some kind of classical Runge-Kutta method of 4 order). It calculates 2 solutions at the end of time step and therefore gives some recommendation for increasing or decreasing of our time step.

\section{NON-DESTRUCTIVE TESTING OF RAILWAY}

In our article grid-characteristic method is the base of numerical simulation of spatial dynamic problem of dynamic loading of complex constructions. One of the problems of this kind is the problem of non-destructive railway testing [25].

In articles [26,27] different kinds of defects in the rails and methods for their investigation are discussed. One can use ultrasonic, magneticfluxleakage, pulsed eddy current technology, automated visual inspection and radiography. Also one can combine these methods for obtain more accurate investigation. For example, one can use both automated visual inspection and pulsed eddy current technology.

Systems for non-destructive testing based on automated visual inspection can estimate the quality of rail profile, study the stage of its deterioration, butt welt, change the location of the sleepers, absence of bolts, surface damages, including deterioration damages specified by contact of wheel and rail, wave shaped deformations of rail top. The speed of work of this system various in wide range (form 1 to $320 \mathrm{~km}$ per hour) in dependence from needed resolution of the image and the type of damage detected. Rather than using of this method do not allow to obtain inner defects.

The ultrasonic method is the most widespread. This method proves to be high quality stuff for high speed (up to $70 \mathrm{~km}$ per hour) for investigating deep subsurface defects (more then $4 \mathrm{~mm}$ from the surface of the rail) and inner defects especially in the rail top and rail web.

This method is developed now and now there are several modifications EMAT (electromagnetic acoustic transducer), long-range ultrasonic, ultrasonic phased array and laser ultrasonic. The computer modeling of physical processes (elastic wave propagation) in rail material is used for its development. There are several approaches for numerical modeling of these processes. For example, in the article [28] finite elements method was used. The comparison of obtained results with physical experiments allows to confirm the possibility of estimating of residual stresses in welded joints. In the article [29] the mass spring model of elastic body was used in the cases of $1 D, 2 D$ and $3 D$ modeling. Authors [30] suggest some modifications of finite difference method in time zone. They use the splitting of $P$-waves and $S$-waves for more understandable imaging of calculated velocity fields. In the article [31] authors obtain the reflection form transverse defect in the rail top. Also they discussed the dependence from its size and orientation. Author used [32] semi-analytical finite element method, $S A F E$ for modeling of wave propagation in waveguides with arbitrary profiles. In the article [33] authors modeled elastic waves propagation in the rail and obtained dynamic wave pattern of velocities and stress tension with different kinds of defects. At the article [34] using $S A F E$ authors modeled wave propagation 
in the rail top, generated by laser. Analysis of obtained results allows to find separated modes, presumably sensitive for some kinds of defects in the rail top. Authors suggested [35] the method for analysis of results of modeling of wave propagation in rail base for detection of point corrosions. At the article [36] numerical study of special wave type, critically refracted longitudinal waves, was done. This study allows to find optimal parameters for generator for physical investigation.

But we should note that in the mentioned articles computer modeling was done using mercantile closed software (ABAQUS, ANSYS and ets.). The absence of detail understanding of used numerical algorithms and the absence of opportunity to estimate correctness of calculations essentially reduces the value of obtained results. We suggest grid-characteristic approach for numerical modeling of ultrasonic non-destructive railway testing. Also we realize the software based on this approach which allows to do numerical experiments. We give some examples [25] using this software.

\subsection{WAVE PROPAGATION IN THE RAIL}

Fig. 1 shows a curvilinear structural mesh for computation of the propagation of

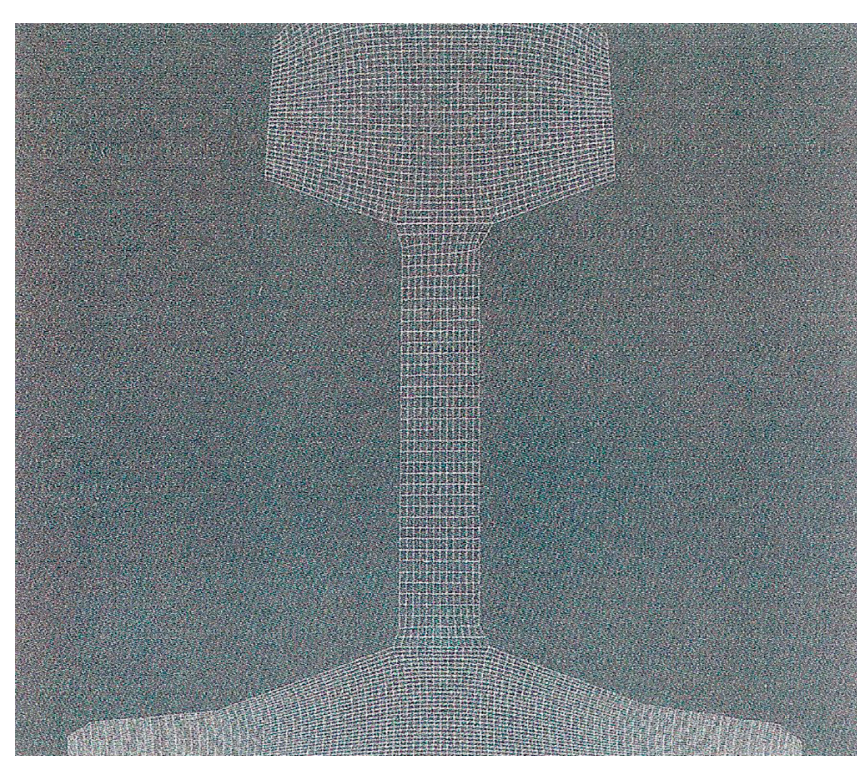

Fig. 1. Rail. Curved structural grids. Profile.

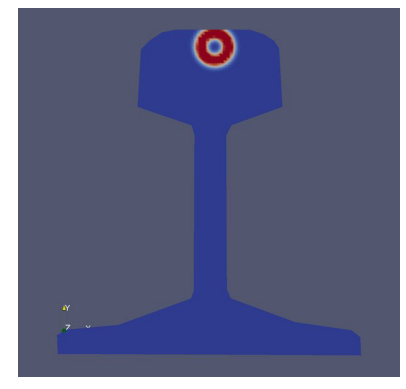

$a$

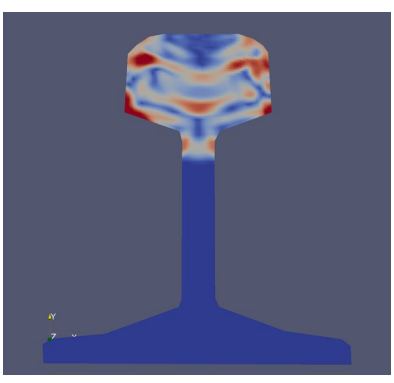

$c$

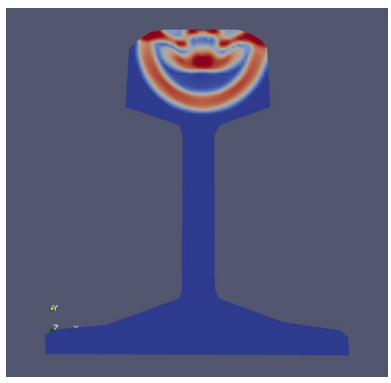

$b$

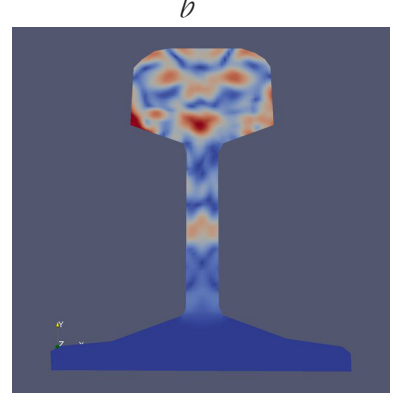

d

Fig. 2. Propagation of elastic waves in the rail. Profile. elastic waves in the rail. This mesh has 100000 nodes. Fig. 2 shows a wave picture arising in the elastic wave passage through the rail. The calculation was made by the grid-characteristic method; the boundaries of integration are free. Figure $2 a$ shows the initial perturbation; Figs. $2 b, c$, and $d$ show the further propagation of the elastic wave in the rail profile.

Fig. 3 shows a characteristic wave picture arising in the propagation in the rail of the elastic wave. For the given calculation a mesh consisting of 100000 nodes and the grid-characteristic method were used, the boundaries of integration are free. Figures 2-4 of the gray gradation show the module of the speed.

The comparison of the calculations by the grid-characteristic method on curvilinear structural grids and by the Galerkin method on nonstructured triangular meshes with the theory of propagation of elastic waves in lattice bars

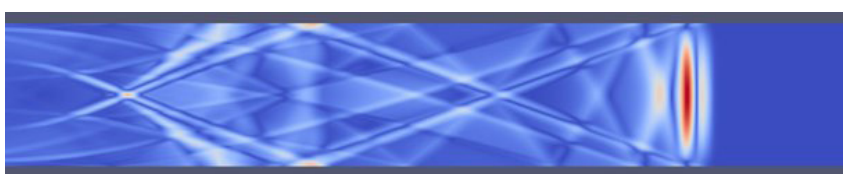

Fig. 3. Propagation of elastic waves in the rail. The typical wave pattern. 

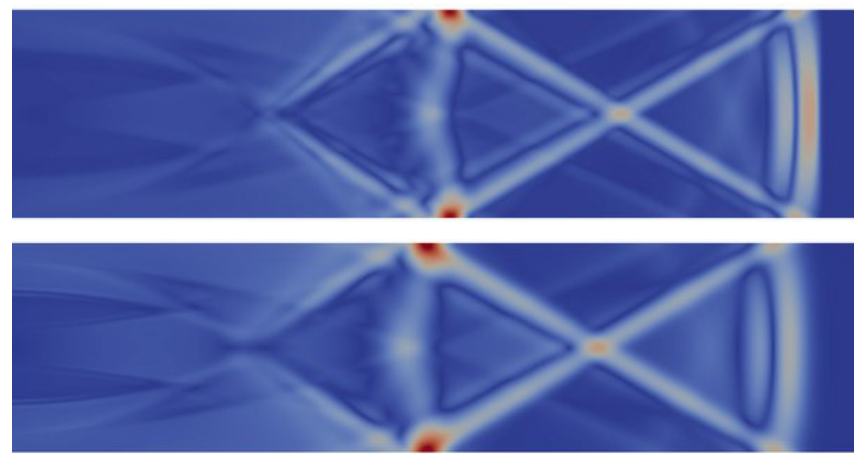

Fig. 4. Propagation of elastic waves in the rail. Comparison of methods: top - grid-characteristic method on curved structured grids; bottom - Galerkin method on unstructured grids

was also made. Fig. 4 shows the comparison of these methods.

Fig. 4 a shows the wave picture obtained by the grid-characteristic method on the curvilinear structural mesh, and Fig. 4b shows the picture obtained by the discontinuous Galerkin method on the non-structural triangular mesh. In both calculations the curvilinear structural and nonstructural triangular meshes, respectively, consisting of 80000 nodes, were used. In both methods the divergence of the calculated speed of sound propagation in rails with the theoretical values is less than $4 \%$.

Let us consider with some additional information several numerical results [25] of wheel rolling, wave passage over the rail with horizontal and vertical defects in the rail top, and comparison of elastic wave propagation in the body of railway bed and embankment in the case of karst cave and without it.

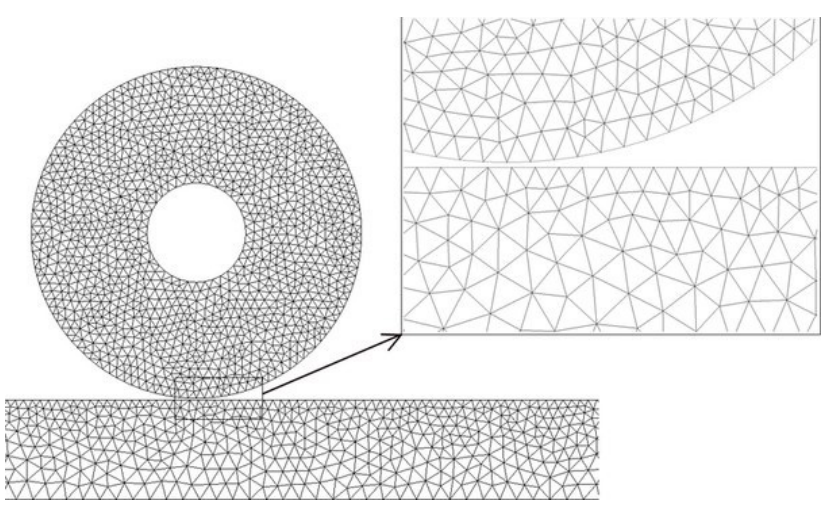

Fig. 5. The mobile system "rail-wheel." The computational grid.

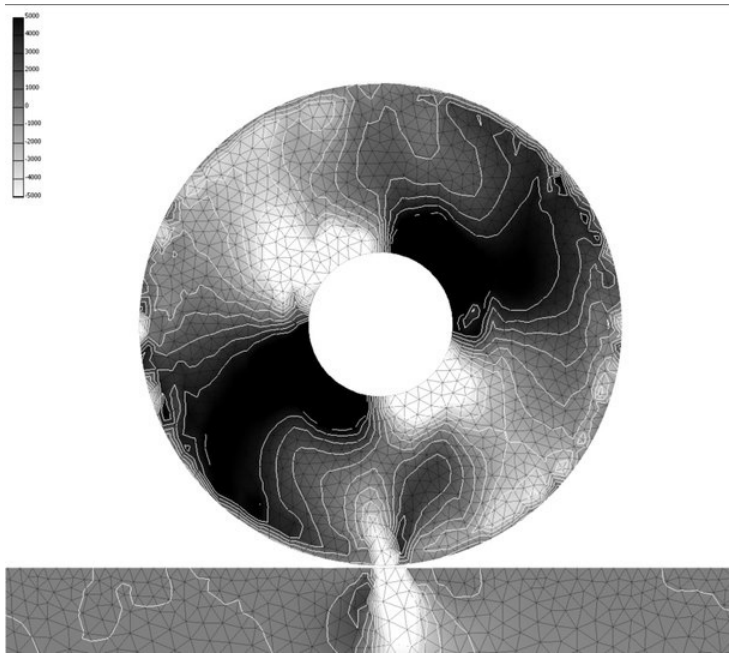

Fig. 6. Propagation of elastic waves in the mobile system "rail - wheel".

\subsection{THE PROPAGATION OF ELASTIC WAVES IN THE MOVING SYSTEM "WHEEL-RAIL"}

Fig. 5 shows the used triangular mesh for numerical simulation of elastic wave propagation in the mobile system "wheel-rail". More details showing the location of contact.

Fig. 6 shows the wave pattern obtained by modeling the propagation of elastic waves in the mobile system "wheel-rail". The result was obtained by using grid-characteristic method on unstructured tetrahedral meshes using the hybrid monotone interpolation. Grayscale shows a component of the stress tensor $\sigma_{y y}$.

Fig. 7 shows the distribution of $\sigma_{\mathrm{xx}}$ in dynamic contact between the wheel and the rail zone. This interface is calculated by means of dynamic friction conditions.
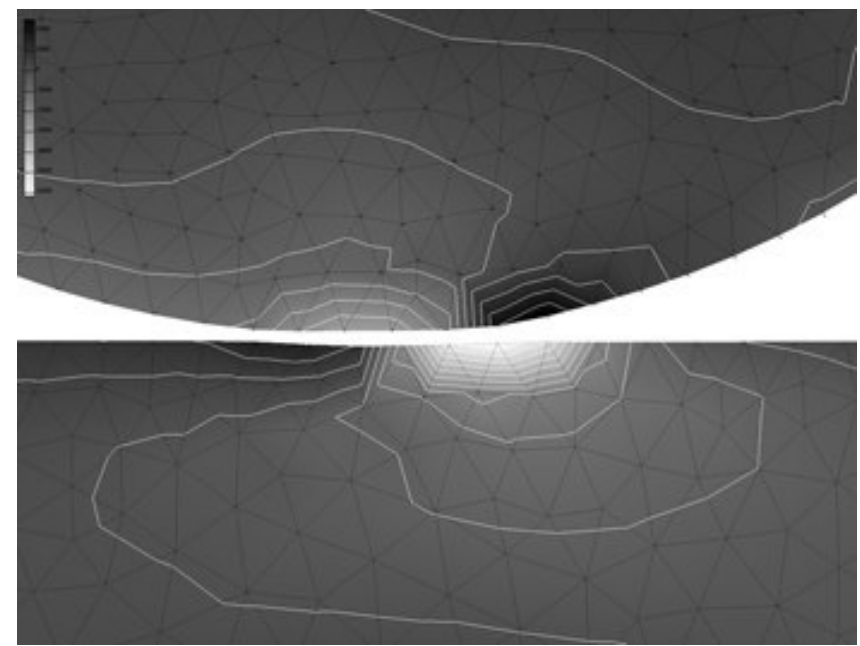

Fig. 7. Calculation of dynamic contact between the wheel and the rail. 


\section{INFORMATION TECHNOLOGIES}

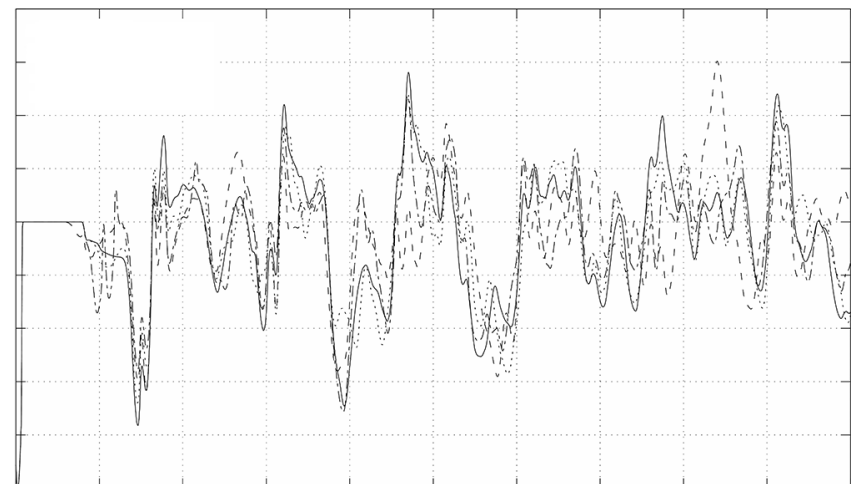

Fig. 8. Dependent of modules of velocity form time (seismic traces) recorded in the intact and damaged rails.

Fig. 8 shows the dependence of the modulus of the speed from time (seismic traces) for the intact rail, the rail top with a vertical stratification, horizontal stratification of rail top and transverse cracks in the rail top. We used grid-characteristic method. The solid line shows the seismic trace for intact rail, dashed - for vertical stratification of the rail top, the dot-dash - with horizontal, shallow dashed - for transverse crack in the rail top.

\subsection{DIAGNOSIS OF DEFECTS OF RAIL IN AN EARLY STAGE OF FORMATION}

The opportunity to diagnose the damage in rail [37] at an early stage of their formation and monitor the dynamics of their development is very interesting. This allows to build more accurate predictions about the planned replacement of infrastructure and detection of small defects that can be dangerous when increasing velocity of the train.

We have considered two types of defects: cracks cluster length $0.5 \mathrm{~mm}$ in the rail head, consisting of 300 evenly distributed cluster of

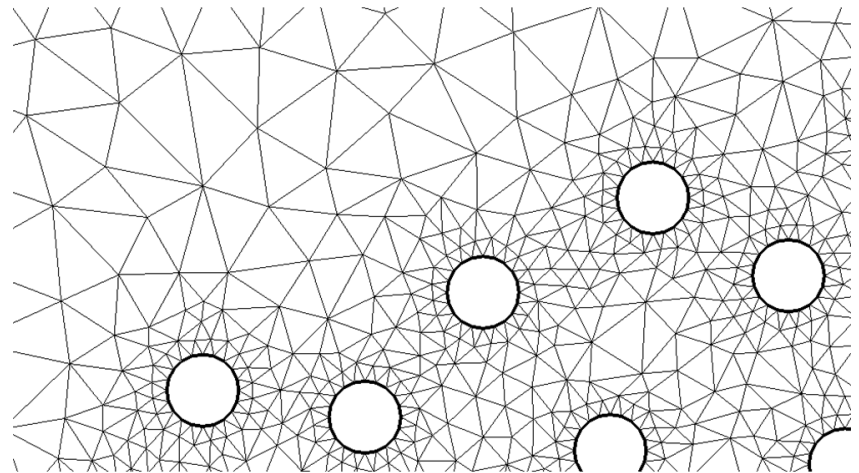

Fig. 9. Triangular grid concentrating around the pores in the rail.

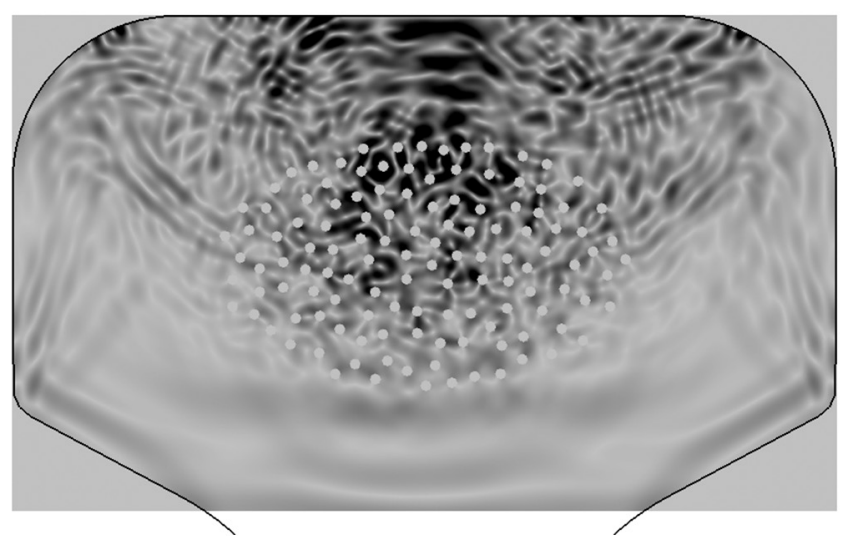

Fig. 10. Wave pattern that occurs during the passage of the elastic waves in the rail with the cluster.

cracks and pores with a diameter of $0.5 \mathrm{~mm}$ in the rail head, consisting of 300 uniformly distributed pores.

Fig. 9 is a tetrahedral mesh, gathering around then, and Fig. 10 - the wave pattern that occurs during the passage of elastic waves through the cluster now. Fig. 10 gray scale shows the speed of the module. This series of numerical experiments was performed using the discontinuous Galerkin method on unstructured triangular meshes.

\subsection{NUMERICAL SIMULATION OF WAVE PATTERN IN THE DAMAGED RAIL}

They are taken from the book [37], where a more detailed list of defects and damage to the rails. Fig. 11 and 12 show photographs of the four types of faults that occur in the rails. Fig. 11 (left side) illustrates a vertical bundle of rail top 30B fault code 1-2. Fig. 11 (right side) is a horizontal separation of the rail top,
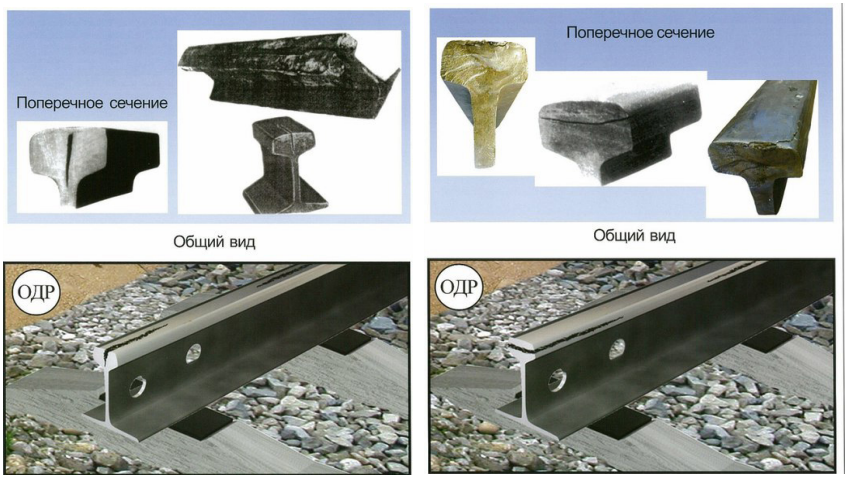

Fig. 11. Stratification head on the left - vertical fault code 30B 1-2, on the right - the horizontal, the code defect $30 \mathrm{~g}$ 1-2. 

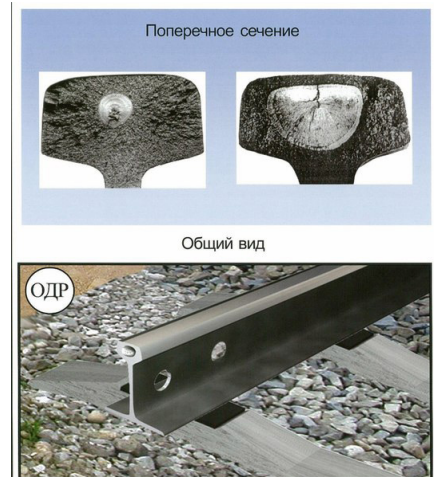

Fig. 12. The transverse crack in the head (on the left), fault code 20 1-2; crack in the neck rail (on the right), fault code 53 1-2.

the code defect $30 \mathrm{~g} 1-2$. Figure 12 (left side) shows a transverse crack in the rail top 20, the defect code 1-2. Fig. 12 (right side) shows a crack in the rail web, defect code 53 1-2.

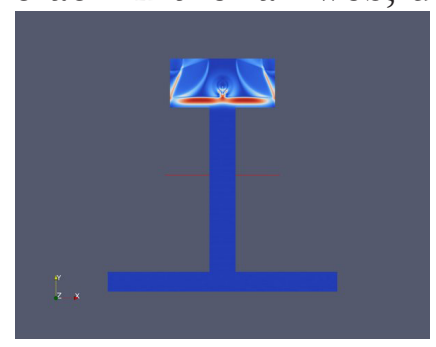

$a$
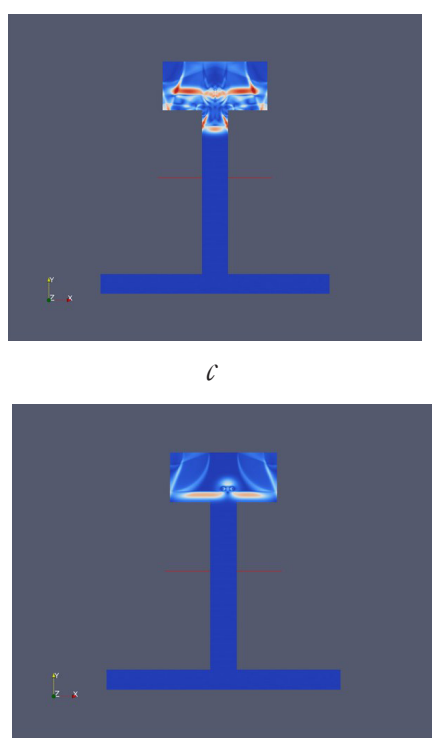

$e$

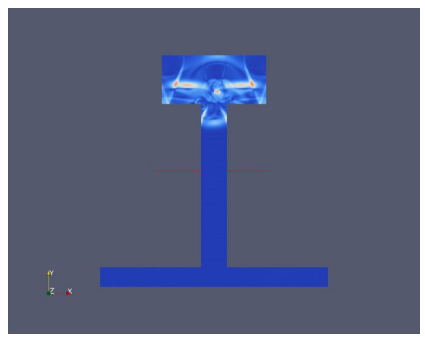

Fig. 13. Propagation of elastic waves in the rail head with the bundle: a vertical - $a, b, c, d$, borizontal - e, f, $g$, b; transverse cracks in the bead-i, k, l, $m$.
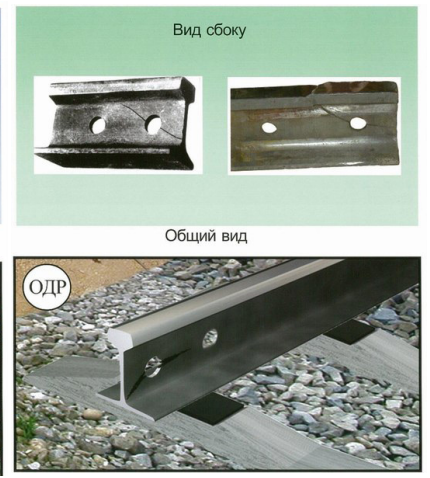

Fig. 13 shows the results of numerical modeling of elastic waves reflected from the vertical stratification of the rail top Fig. 13a, $b, c, d$ shows reflected waves in the early stages of formation; figure 13e, $f, g, h$ shows reflected waves from horizontal one; Fig. 14a, $b, c, d$ shows reflected waves in the transverse cracks in the rail top, as in the initial stage of formation. Fig. 14e, $f, g, b$ for comparison shows the wave pattern in the rail without damage at the same time. Fig. $13 a, e$ and $14 a$ shows the elastic wave reflected from the defect; in Figures 13b, $f$ and $14 b$ - the further formation of the first response; Figures $13 c, 14 c$, and $g$ - generating a second response from the reflection from the boundary elastic

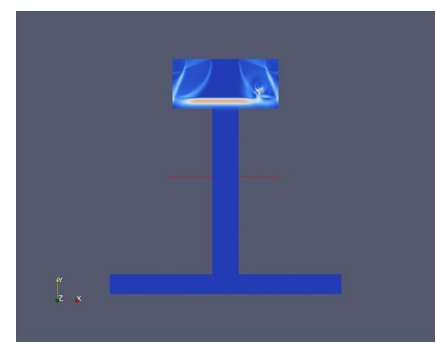

$a$

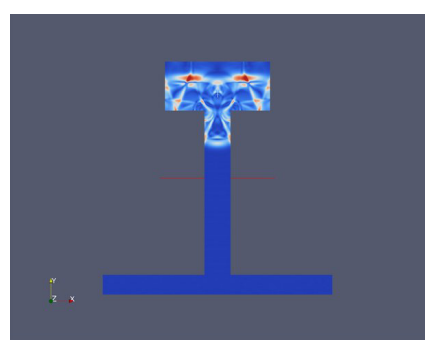

$d$

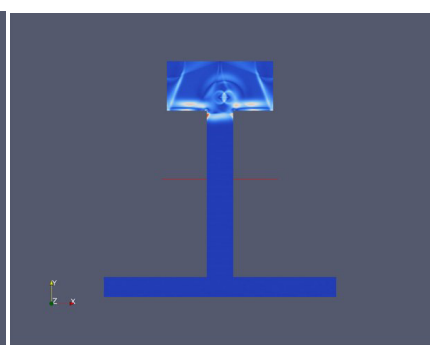

f

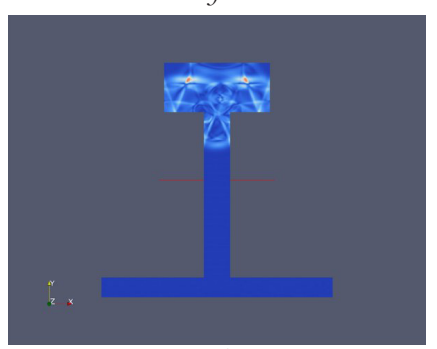

h

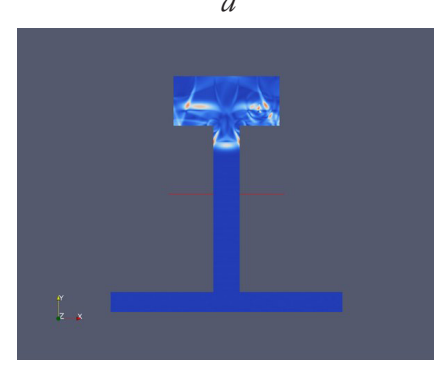

$c$

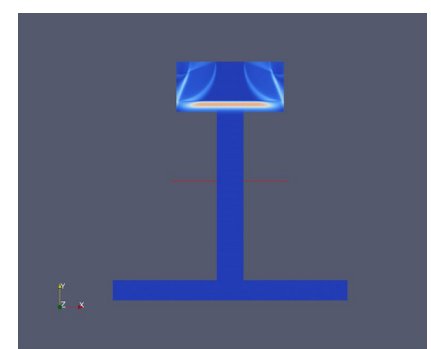

$e$

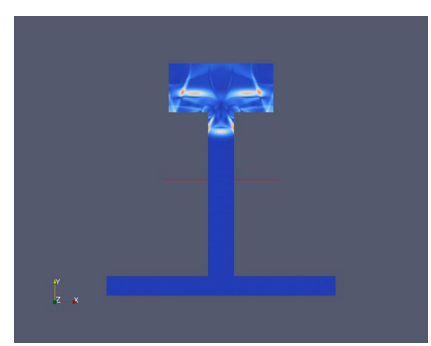

$g$

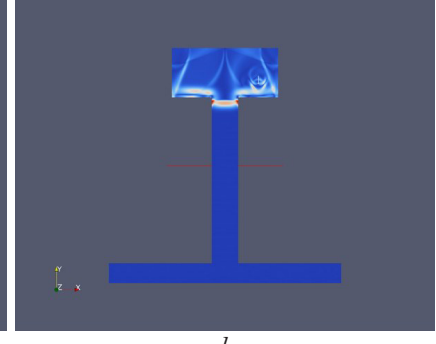

$b$

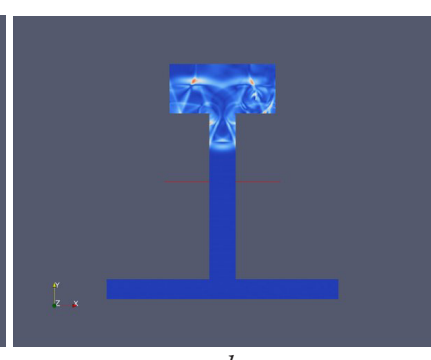

$d$

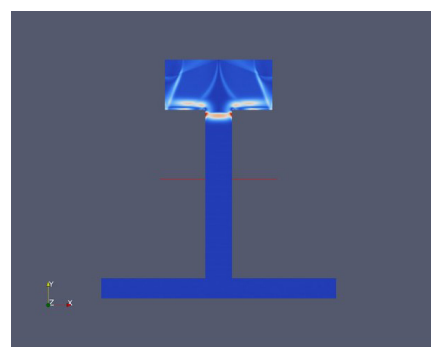

f

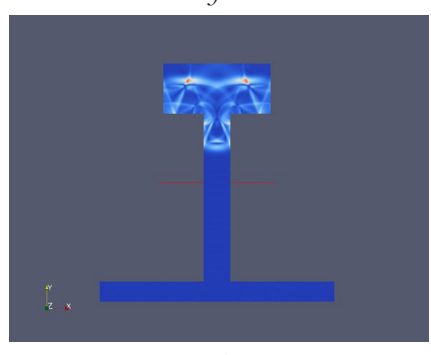

b
Fig. 14. Propagation of elastic waves in the rail transverse cracks in the head - i, k, l, m; Intact rail - n, o, p, r. 


\section{INFORMATION TECHNOLOGIES}

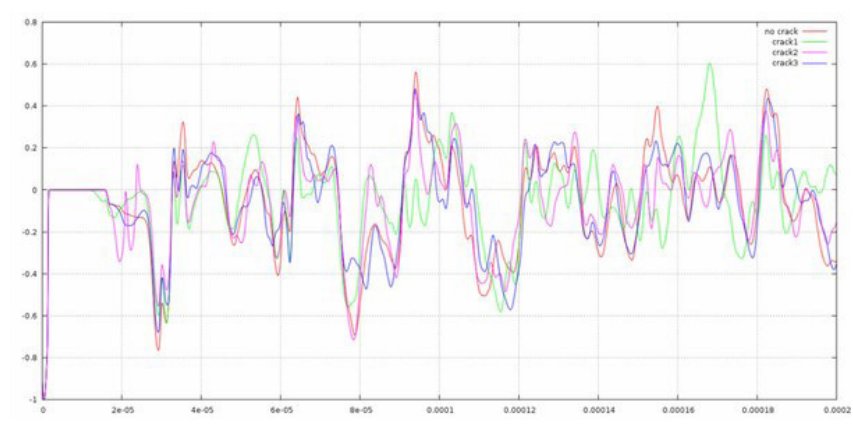

Fig. 15. Dependence of $v(t)$ (seismic traces), recorded in the damaged rails.

wave of the rail; the Figures $13 d, b$ and $14 d-$ further forming a second response; Fig. 13-14 color shows the module of velocity in the rail.

Fig. 15 shows the dependence of $v(t)$ (seismic traces), recorded in the damaged rails. The red color shows the seismic trace for intact rail, green - with a vertical stratification of the rail top, violet shows the rail with horizontal one, blue shows the rail with a transverse crack in the rail top. It is evident that in the initial stages of the seismic traces differ substantially for the intact rail and rail with defects.

Fig. 16 shows the formation of a response from a crack in the rail web. In the upper figure it corresponds to the initial stage of damage, and the damage on the ground have expressed brighter. The colors shown in the module of velocity.
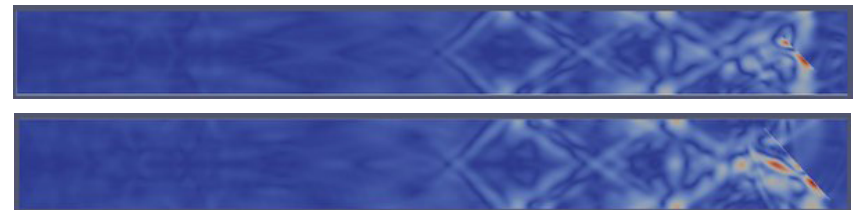

Fig. 16. Formation of a response from a crack in the rail web: top - the initial stage of the damage below - advanced stage of damage

Fig. 17 shows dependences of horizontal component of velociti from time $v_{x}(t)$ (seismic traces), blue color shows this dependence for intact

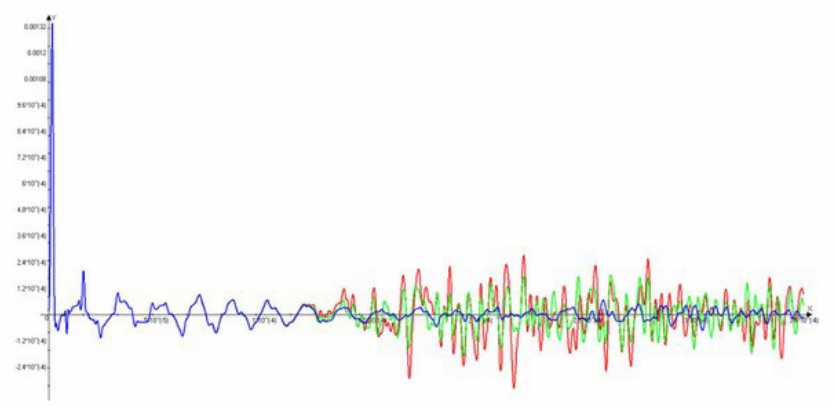

Fig. 17. Dependence of $v(t)$ (seismic traces), intact and rail tracks with a crack in the neck lengths.
АНОАНЫЕ МАТЕРИА $Ы$ НА ОСНОВЕ ГРАФЕНА АИЯ АИТИЙ-ИОННЫХ АККУМУ АЯТОРОВ

rail, green color shows this dependence in the case of initial stage of damage, and red color shows this dependence for the next stage or rail damage.

\subsection{PROPAGATION OF ULTRASONIC WAVES IN THE PROFILE OF THE RAIL TOP WITH A HORIZONTAL BUNDLE}

Numerical simulation of ultrasonic wave propagation in the profile of the rail $R-65$. It presupposes the existence of the defect with code 30G [37] (the horizontal stratification of the metal rail top) right in the middle of the rail top.

Piezoelement, exciting the signal, was modeled using the application to the square with the size of $15 \mathrm{~mm}$ at the horizontal surface of the rail top of traction that varies sinusoidally (wavelength emitter is $1 \mathrm{~mm}$, the frequency of the emitter is equal to $6.25 \mathrm{MHz}$ ). The amplitude of the traction was equal to $1 \mathrm{~N}$. The initial phase equals 0 . Rail material was steel, with parameters $\lambda=146.1 \times 10^{9} \mathrm{~Pa}, \mu=79.3 \times 10^{9} \mathrm{~Pa}, \varrho=7.8 \times 10^{3}$ $\mathrm{kg} / \mathrm{m}^{3}, c_{p}=6250 \mathrm{~m} / \mathrm{s}$. The harmonic signal modulated rectangular meander with duration of 10 periods.

The signal receiver and the piezoelement located on the surface of the rail top at the axis of symmetry. The signal receiver measured velocity components. The calculation is performed in the two-dimensional formulation. We used the triangular unstructured computational grid with 104 cells, shown at Fig. 18. The grid is built

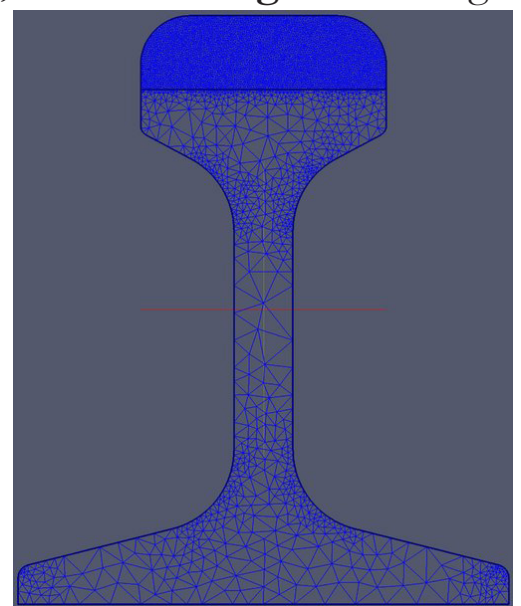

Fig. 18. Propagation of ultrasonic waves in the rail top with a horizontal bundle. The computational grid. 
using the library generating triangular grids. We used discontinuous Galerkin method with the Lagrange polynomial of order 6 . Integration over time with the help of 7-step method DormandPrince of 5 order accuracy and with adaptive time step. The bundle was located at a distance of $22.5 \mathrm{~mm}$ from the surface of the rail top and simulated with the help of the free boundary.

Fig. 19a, $b, c$ illustrates the formation of diagnosing wave time $1 \mathrm{~ms}$. Fig. 19d, e, $f$ shown formed spherical shear wave at time $3 \mathrm{~ms}$ and shown further spread of diagnosing wave. Fig.

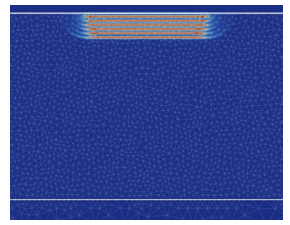

$a$

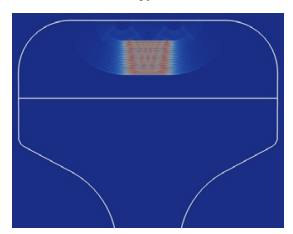

$d$

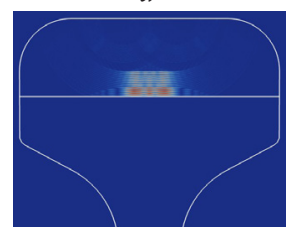

$g$
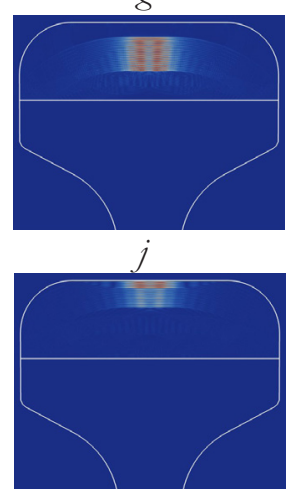

$m$

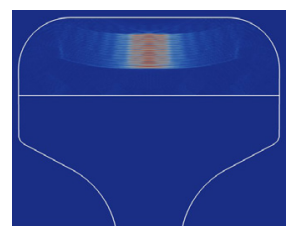

$q$

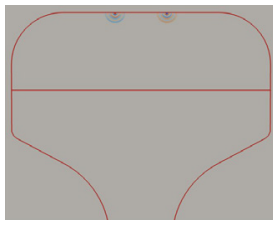

$b$

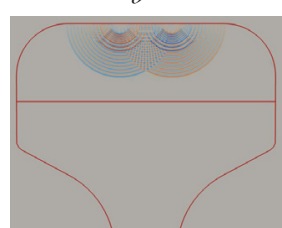

$e$

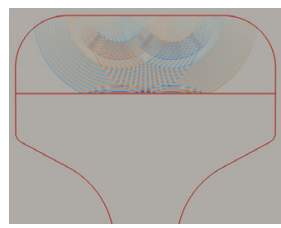

b

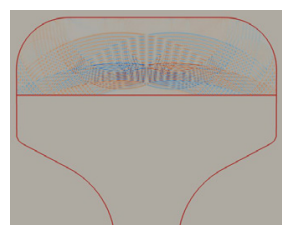

k

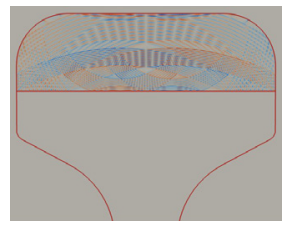

$n$

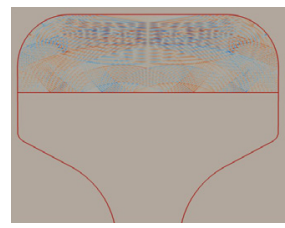

$r$

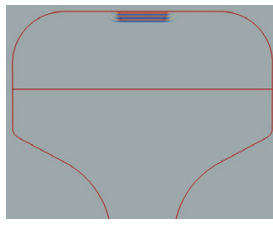

$c$

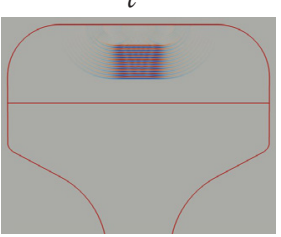

f

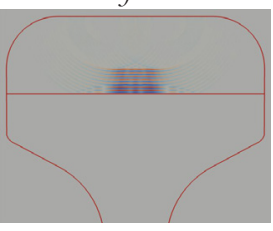

i

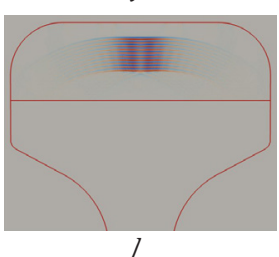

l

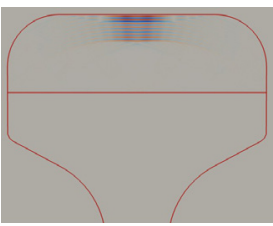

$p$

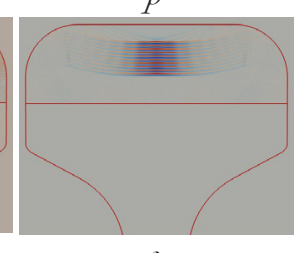

$s$

Fig. 19. Propagation of ultrasonic waves in the rail top with a horizontal bundle: $a, b, c$ - the formation of a wave, $d, e, f$ - the wave propagation, $g, h, i$-formation response, $j, k, l$ - distribution response, $m, n, p$ - reflection from the boundary, $q, r, s$ - distribution of the reflected wave.

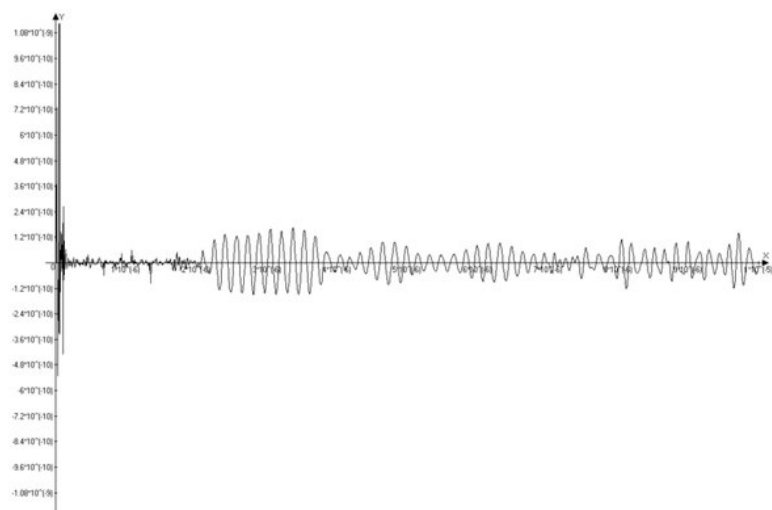

Fig. 20. Propagation of ultrasonic waves in the rail top with a horizontal bundle. Dependence vx (t) (seismic trace).

$19 g, h, i$ shows the formation of a response from the head of the horizontal bundle at time $4 \mathrm{~ms}$. Fig. $19 j, k, l$ shows distribution response to a sensor on the surface of the rail, at time $7 \mathrm{~ms}$. Fig. $19 m, n, p$ shows reflection response from the rail surface at time $8 \mathrm{~ms}$. Fig. 19q, $r$, s shows the formed reflected wave from the surface of the rail at time $10 \mathrm{~ms}$. Fig. $19 a, d, g, j, m, q$ color shows the modulus of the velocity, in Fig. 19b, e, b, k, n, $r$ shows a horizontal component of velocity, in Fig. 19c, f, $i, l, p, s$ shows vertical component of velocity.

Fig. 20 shows the dependence $v_{x}(t)$ (seismic trace) and Fig. 21 shows $v_{y}(t)$. The response was expected after a time $2 \times 22.5 / c_{p}=7.2 \times 10^{-6} \mathrm{~s}$, which is consistent with the calculated data.

Pay attention to two facts. Firstly, the amplitude of the return signal from the defect on the receiver more than on the emitted signal. This is due to the fact that the rate does

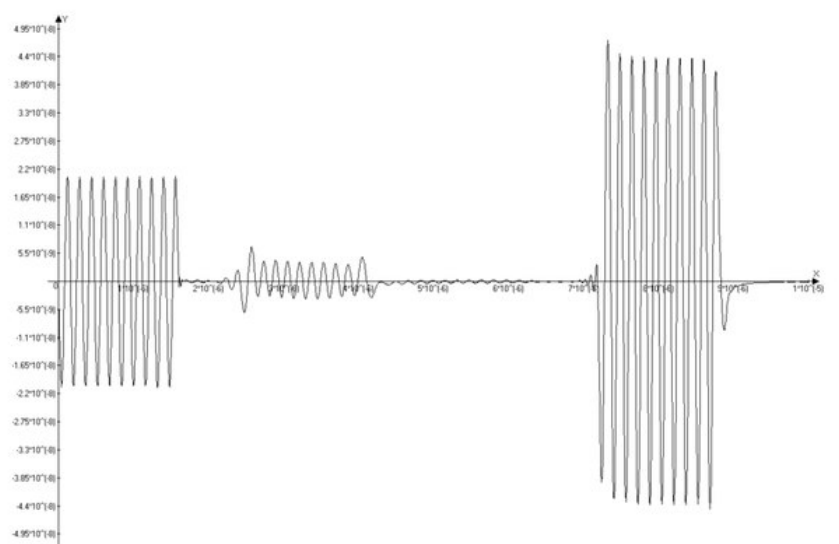

Fig. 21. Propagation of ultrasonic waves in the rail top with a horizontal bundle. Dependence vy (t) (seismic trace). 
not change phase upon reflection from a free surface and interferes with itself. Secondly, in the range of from $2.5 \times 10^{-6}$ to $4 \times 10^{-6}$ perturbation is observed, that is comparable in amplitude to the signal source. This is due to the diffraction pattern occurring at the edges of the piezoelectric element.

\subsection{FINDING THE INCLUSION OF KARST IN THE GROUND UNDER THE EMBANKMENT}

Fig. 22 shows the initial perturbation to calculate the wave pattern in the ground with the inclusion of karst (a) and without it (b). Fig. 22a-b shows by color the module of velocity. Fig. $22 c, d$ displays the further propagation of elastic waves in the rail embankment and the ground. Fig. 22e, $f$ displayed generating a first response from the inclusion of karst, and Fig. 22g, $b$ shows the second one.

Red corresponds to the calculation without inclusion of karst, and blue - with the inclusion of karst.

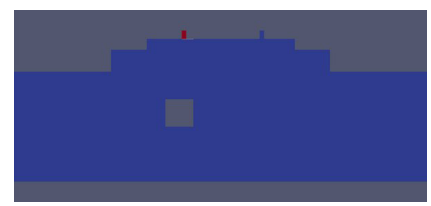

$a$

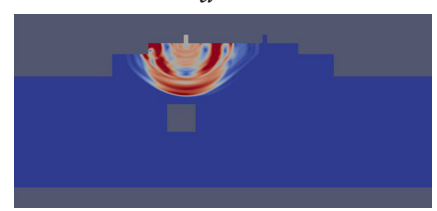

$c$

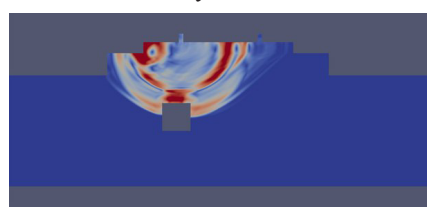

$e$

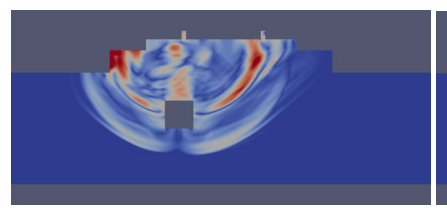

$g$

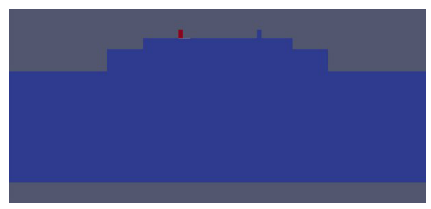

$b$

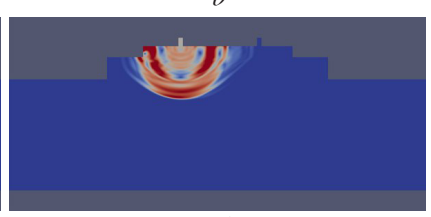

$d$

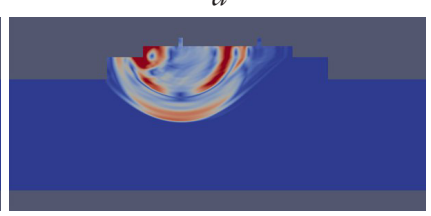

$f$

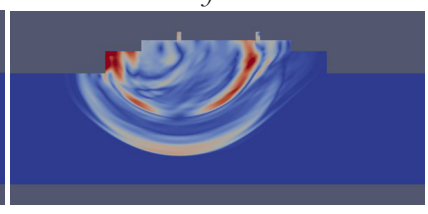

$b$
Fig. 22. Propagation of elastic waves in the railway embankment: $a, b$ - the initial perturbation, with a cavity (a), without the cavity (b); $c, d$ - spread perturbations with a cavity (c), without a cavity (d); $e$, $f$-forming a first response with a cavity (e), the same time without a cavity (f); $g, b$-forming a second response with a cavity (g), the same time without the cavity (b).

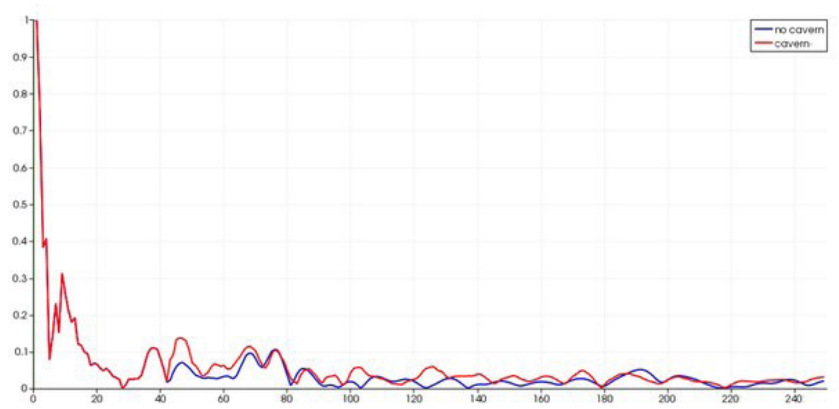

Fig. 23. Dependence of $v(t)$ (seismic trace), measured on the left rail.

Fig. 23, 24 shows dependences $v(t)$ (seismic traces), obtained from the left rail and from the right rail accordingly. Both in the Fig. 23, 24 red color shows the case without the inclusion of karst and blue color shows the case with the inclusion of karst.

\section{CONCLUSION}

Grid-characteristic method of high accuracy on tetrahedral hierarchical grids using high order interpolation and multiple time step was developed and was used for numerical simulation of wave propagation in threedimensional problems of dynamic loading of complex structures. The basic elements of the method was discussed in this work. The developed algorithm is implemented on highperformance computing systems. We carried out a series of numerical experiments using the method for solving problems of non-destructive railway testig. It is shown that the method provides a high temporal and spatial resolution, and to calculate the components of the stress tensor and vector of velocity at any point in the construction under consideration. It also allows you to explore the effect of the destroyed areas on the wave pattern of damage. The use of

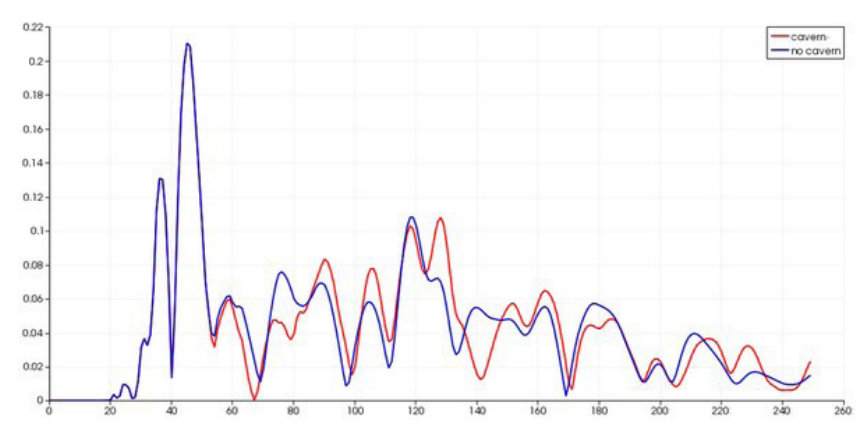

Fig. 24. Dependence of $v(t)$ (seismic trace), measured on the right rail 
accumulated experience in this area will greatly accelerate the development of effective methods of non-destructive railway testing.

The study was supported by RFBR under the research project number 13-07-13169 ofi_m_RZhD.

\section{REFERENCES}

1. Novatsky VK. Teoriya uprugosti [Theory of elasticity]. Moscow, Mir Publ., 1975, 872 p.

2. Kondaurov VI, Fortov VE. Osnovy termomekhaniki kondensirovannoy sredy [Fundamentals of thermomechanics of condensed matter]. Moscow, MFTI Publ., 2002, 123 p.

3. Magomedov KM, Kholodov AS. O postroenii raznostnykh skhem dlya uravneniy giperbolicheskogo tipa na osnove kharakteristicheskikh sootnosheniy [About the construction of difference schemes for equations of hyperbolic type on the basis of characteristic ratios]. Zhurnal vychislitelnoy matematiki i matematicheskoy fisiki, 1969, 9(2):373-386 (in Russ.).

4. Magomedov KM, Kholodov AS. Setochnokharakteristicheskie chislennye metody [Gridcharacteristic numerical methods]. Moscow, Nauka Publ., 1988, 123 p.

5. Ivanov VD, Kondaurov VI, Petrov IB, Kholodov AS. Raschet dinamicheskogo deformirovaniya i razrusheniya uprugoplasticheskikh tel setochnokharakteristicheskimi metodami [Calculation of the dynamic deformation and fracture of elastoplastic bodies by use grid-characteristic methods]. Matematicheskoe Modelirovanie, 1990, 2(11):10-29 (in Russ.).

6. Petrov IB, Lobanov AI. Lektsii po yychislitel'noy matematike [Lectures on Computational Mathematics]. Moscow, Internet-universitet informatsionnykh tekhnologiy Publ., 2006, 123 c.

7. Petrov IB, Favorskaya AB. Biblioteka po interpolyatsii vysokikh poryadkov na nestrukturirovannykh treugolnykh i tetraedralnykh setkakh [Library of high-order interpolation on unstructured triangular and tetrahedral grids. Infomatsionnye tekhnologii, 2011, 9:30-32 (in Russ.).

8. Petrov IB, Favorskaya AB, Sannikiov AV, Kvasov IE. Setochno-kharakteristicheskiy metod $\mathrm{s}$ ispolzovaniem interpolyatsii vysokikh poryadkov na tetraedralnykh ierarkhicheskikh setkakh $\mathrm{s}$ kratnym shagom po vremeni [Grid-characteristic method using high order interpolation using tetrahedral hierarchical meshes with multiple time step]. Matematicheskoe modelirovanie, 2013, 25(2):4252 (in Russ.).

9. Muratov MV, Petrov IB, Sannikov AV, Favorskaya AV. Setochno-kharakteristicheskiy metod na nestrukturirovannykh tetraedralnykh setkakh [Gridcharacteristic method on unstructured tetrahedral grids]. Zhurnal yychislitelnoy matematiki i matematicheskoy fisiki, 2014, 54(5):821-832 (in Russ.).

10. Petrov IB, Kholodov NI. Modelirovanie zadach 3D seysmiki na vasokoproizvoditelnykh vychislitelnykh sistemakh [Simulation of 3D seismic problems on High Performance Computing Systems]. Matematicheskoe modelirovanie, 2014, 26(1):83-95 (in Russ.).

11. Käser M, Dumbser M. An arbitrary high-oder discontinuous Galerkin method for elastic waves on unstructured meshes - I.The two-dimensional isotropic case with external source terms. Geophysical Journal International, 2006, 66(2):855-877.

12. Kvasov IE, Petrov IB, Chelnokov FB. Raschet volnovykh protsessov $\mathrm{V}$ neodnorodnykh prostranstvennykh konstruktsiyakh [Calculation of wave processes in inhomogeneous spatial structures]. Matematicheskoe modelirovanie, 2009, 21(5):3-9 (in Russ.).

13. Kvasov IE, Petrov IB, Sannikov AV, Favorskaya AV. Setochno-kharakteristicheskiy metod vysokoy tochnosti na tetraedralnykh ierarkhicheskikh setkakh s kratnym shagom po vremeni [Gridcharacteristic method of high accuracy on tetrahedral hierarchical meshes with multiple time step]. Komp'yuternye issledovaniya i modelirovanie, 2012, 3(1):161-171 (in Russ.).

14. Petrov IB, Kholodov AS. Chislennoe issledovanie nekotorykh dinamicheskikh zadach mekhaniki deformiruemogo tverdogo tela setochnokharakteristicheskim metodom [Numerical investigation of some dynamic problems of mechanics of devormable solids using gridcharacteristic method.] Zhurnal vychislitelnoy matematiki i matematicheskoy fisiki, 1984, 24(5):722739 (in Russ.).

15. Ami Harten. High resolution schemes for hyperbolic conaervation laws. J. of Comp. Physics, 1997, 135(2):337-365.

16. Petrov IB, Khokhlov NI. Sravnenie TVD limiterov dlya chislennogo resheniya uravneniy dinamiki deformiruemogo tverdogo tela setochnokharakteristicheskim metodom [Compare TVD limiters for the numerical solution of equations 
of the dynamics of deformable solids using gridcharacteristic method]. Matematicheskie modeli $i$ radachi upravleniya. Moscow, MFTI Publ., 2011, pp. 104-111.

17. Roe PL. Characteristic-Based Schemes for the Euler Equation. Annual Review of Fluid Mechanics, 1986, 18:337-365.

18. Kholodov AS, Kholodov YaA. O kriteriyakh monotonnosti raznostnykh skhem dlya uravneniya giperbolicheskogo tipa [On the criteria of monotone difference schemes for hyperbolic equation]. Zhurnal yychislitelnoy matematiki i matematicheskoy fisiki,, 2006, 46(9):1560-1588 (in Russ.).

19. Miryakha VA, Sannikov AV, Petrov IB. Chislennoe modelirovanie volnovykh processov $\mathrm{v}$ gidrouprugikh zadachakh razryvnym metodom Galerkina na nestrukturirovannykh treugolnykh setkakh [Numerical modeling of wave processes in hydroelastic problems using discontinuous Galerkin method on unstructured triangular meshes]. Vestnik Baltiyskogo federalnogo universiteta im. I.Kanta. 2014, 10:16-20 (in Russ.).

20. Wilcox LC, Stadler G, Burstedde C. et al. A highorder discontinuous Galerkin method for wave propagation through coupled elastic-acoustic media. J. of Comp.Phys., 2010, 229:9373-9396.

21. LeVeque RL. Finite volume methods for byperbolic problems. Cambridge, 2002.

22. Hesthaven JS, Warburton T. Nodal discontinuous Galerkin methods: algorithms, analysis, and applications. Texts in Applied Mathematics. Springer, 2008, vol. 54.

23. Dormand JR, Prince PJ. A family of embedded Runge-Kutta formulae. Journal of Computational and Applied Mathematics, 1980, 6(1):19-26, doi:10.1016/0771-050X(80)90013-3

24. Hairer E, Nørsett SP, Wanner G. Solving ordinary differential equations I: Nonstiff problems. Berlin, New York: Springer-Verlag, 2008.

25. Petrov IB, Golubev VI, Miryakha VA, Khokhlov NI, Favorskaya AV, Sannikov AV, Beklemysheva KA. Dinamicheskaya diagnostika elementov puti [Dynamic diagnosis of path elements]. Tekhnika zheleznykh dorog, 2013, 4:64-77 (in Russ.).

26. Cannon DF, Edel K-O, Grassie SL, Sawley K. Rail defects: an overview. Fatigue \& Fracture of Engineering Materials \& Structures, 2003, 26(10):865-886.

27. Papaelias MPh, Roberts C, Davis CL. A review on non-destructive evaluation of rails: State-of-the-art and future development. Journal of Rail and Rapid Transit, 2008, 222(4):367-384.

28. Dzhavadi Ya, Nadzhafabadi MA, Akhlagi M.
Otsenka ostatochnykh napryazheniy $\mathrm{v}$ svarnykh soedineniyakh iz raznorodnykh komponent $\mathrm{s}$ ispolzovaniem modelirovaniya metodom konechnykh elementov i izmereniya golovnoy ultrazvukovoy volny [Evaluation of residual stresses in welded joints of dissimilar component using the modeling by finite element method and the measurement head ultrasonic waves]. Defektoskopiya, 2012, 9:48-61 (in Russ.).

29. Sych TV, Gerasimov SI, Kuleshov VK. Modelirovanie rasprostraneniya akusticheskikh voln metodom konechnykh elementov [Modeling the propagation of acoustic waves using finite element method]. Defektoskopiya, 2012, 3:3-9 (in Russ.).

30. Barkhatov VA. Modelirovanie yltrazvukovykh voln metodom konechnykh raznostey vo vremennoy oblasti. Dvumernaya zadacha. Optimalnye algoritmy. Analiz pogreshnostey. Pogloschayuschie oblasti vblizi granits setok [Modeling of ultrasonic waves by a finite difference method in the time domain. The two-dimensional problem. Optimal algorithms. Analysis of errors. Absorbing regions near the boundaries of the grids]. Defektoskopiya, 2009, 6:76-82 (in Russ.).

31. Bartoli I, di Scalea FL, Fateh M, Viola E. Modeling guided wave propagation with application to the long-range defect detection in railroad tracks. NDT\&E International, 2005, 38(5):325-334.

32. Bartoli I, Marzani A, di Scale'a FL, Viola E. Modeling wave propagation in damped waveguides of arbitrary cross-section. NDT8cE International, 2006, 295(3-5):685707.

33. Zumpano G, Meo M. A new damage detection technique based on wave propagation for rails. Intern. Journal of Solids and Structures, 2006, 43:10231046.

34. Coccia S, Bartoli I, Marzani A, di Scalea FL, Salamone S, Fateh M. Numerical and experimental study of guided waves for detection of defects in the rail head. NDT\&E International, 2011, 44:93100.

35. Cerniglia D, Pantano A, Vento MA. Guided wave propagation in a plate edge and application to NDI of rail base. Journal Nondestuct Eval., 2012, 31:245-252.

36. Chaki S, Ke W, Demouveau H. Numerical and experimental analysis of the critically refracted longitudinal beam. Ultrasonics, 2013, 53(1):65-69.

37. Gritsyk VI. Defekty relsov zheleznodorozhnogo puti [Defects of rails of a railway track]. Moscow, Marsgrut Publ., 2005, 80 p. 